\title{
TWO NEW SPECIES OF ORIBATID MITES OF THE GENUS XENILLUS (ACARI, ORIBATIDA, LIACARIDAE) FROM BOLIVIA
}

\author{
Sergey G. Ermilov ${ }^{1}$ and Josef Starý ${ }^{2}$ \\ ${ }^{1}$ Tyumen State University, Institute of Environmental and Agricultural Biology (X-BIO) \\ Lenina str. 25, 625000 Tyumen, Russia \\ E-mail:ermilovacari@yandex.ru; https://orcid.org/0000-0002-0913-131X \\ ${ }^{2}$ Biology Centre v.v.i., Czech Academy of Sciences, Institute of Soil Biology \\ Na Sádkách 7, 37005 České Budějovice, Czech Republic \\ E-mail: jstary@upb.cas.cz; https://orcid.org/0000-0002-9440-4254
}

Two new species of oribatid mites of the genus Xenillus (Oribatida, Liacaridae) are described from leaf litter in a rain forest in Bolivia. Xenillus pseudobolivianus sp. $\mathrm{n}$. is similar to $X$. bolivianus and $X$. neonominatus in the morphology of lamellar cusp, length of bothridial and interlamellar setae and length and morphology of dorsal notogastral setae, but differs from both by the morphology of bothridial head and interlamellar and notogastral setae, the ornamentation of the notogaster, and the different length of some notogastral setae. Xenillus amboroensis sp. $\mathrm{n}$. is similar to $X$. amazonensis, $X$. disjunctus, $X$. diversisetosus, $X$. fecundus, X. longipes, and X. ornatus in the morphology of bothridial seta, but differs from all by the morphology of lamellar cusp, the placement of the lamellar seta, and the different length of some notogastral setae.

Key words: Oribatida, Bolivia, taxonomy, morphology.

\section{INTRODUCTION}

Presently, oribatid mites (Acari, Oribatida) of the family Liacaridae are briefly studied in Bolivia, where only a few species have been recorded (e.g. Balogh \& Mahunka 1969, J. Balogh \& P. Balogh 1985). During the taxonomic identification of a random set of previously unstudied Bolivian materials, which were received from the collections of the Institute of Soil Biology (České Budějovice, Czech Republic), we found two new species belonging to the genus Xenillus Robineau-Desvoidy, 1839. The main goal of the paper is to describe and illustrate these new species.

The genus Xenillus was proposed by Robineau-Desvoidy (1839), with Xenillus clypeator Robineau-Desvoidy, 1839 as type species. The genus comprises two subgenera and 79 species distributed in the Holarctic, Oriental and Neotropical regions (Subías 2021). The main generic traits have been summarized by several authors (e.g., Grobler et al. 2003, Weigmann 2006). P. Balogh $(1985,1986)$ and J. BAlOGH and P. BAlogh $(1988,2002)$ created identification keys to species from the Neotropical region. 


\section{MATERIAL AND METHODS}

Specimens. The specimens of the new species were kindly provided by the Institute of Soil Biology, České Budějovice, Czech Republic; the collection localities are given in the Material examined section. Specimens are deposited in two institutions: the Senckenberg Museum of Natural History, Görlitz, Germany (SMNH); and the Tyumen State University Museum of Zoology, Tyumen, Russia (TSUMZ).

Observation and documentation. Specimens were mounted in lactic acid on temporary cavity slides for measurements and illustrations. Body length was measured in lateral view, from the tip of the rostrum to the posterior edge of the notogaster. Notogastral width refers to the maximum width of the notogaster in dorsal view. Lengths of body setae were measured in lateral aspect. All body measurements are presented in micrometers. Formulas for leg setation are given in parentheses according to the sequence trochanterfemur-genu-tibia-tarsus (famulus included). Formulas for leg solenidia are given in square brackets according to the sequence genu-tibia-tarsus. Drawings were made with a camera lucida using a Leica transmission light microscope "Leica DM 2500". SEM micrographs were made with the aid of a JEOL-JSM-6510LV SEM microscope.

Terminology. General morphological terminology used in this paper mostly follows that of F. Grandjean (see Travé \& VACHON (1975) for references), Norton (1977), Mahunka and Zombori (1985), and Norton and Behan-Pelletier (2009).

Abbreviations. Prodorsum: lam = lamella; $r o, l e, i n, b s=$ rostral, lamellar, interlamellar, and bothridial seta, respectively; $t u=$ tutorium; $P=$ pleurophragma. Notogaster: $c, l a$, $l m, l p, h, p=$ notogastral setae; $i a, i m, i p, i h, i p s=$ notogastral lyrifissures; $g l a=$ opisthonotal gland opening. Gnathosoma: $a, m, h=$ subcapitular setae; or = adoral seta; $d, l$, sup, inf, cm, $u l, s u, v t, l t=$ palp setae; $\omega=$ palp solenidion; $c h a, c h b=$ cheliceral setae; $T g=$ Trägårdh's organ. Epimeral and lateral podosomal regions: $1 a-1 c, 2 a, 3 a-3 c, 4 a-4 c=$ epimeral setae; $P d I=$ pedotectum I; dis = discidium; $c p c=$ circumpedal carina. Anogenital region: $g, a g, a n, a d=$ genital, aggenital, anal, and adanal setae, respectively; $i a d=$ adanal lyrifissure; $p o=$ preanal organ. Legs: $\mathrm{Tr}, \mathrm{Fe}, \mathrm{Ge}, \mathrm{Ti}, \mathrm{Ta}=\mathrm{leg}$ trochanter, femur, genu, tibia, tarsus, respectively; fet = femur tubercle; fep = femur process; $\operatorname{tr} p=$ trochanter process; $\omega, \phi, \sigma=$ leg solenidia; $\varepsilon=$ leg famulus; $d, l, v, b v, e v, f t, t c, i t, p, u, a, s, p v, p l=$ leg setae; $p a=$ porose area.

\section{TAXONOMY}

Family Liacaridae Sellnick, 1928

Genus Xenillus Robineau-Desvoidy, 1839

Type species: Xenillus clypeator Robineau-Desvoidy, 1839

Xenillus pseudobolivianus Ermilov et Starý sp. n.

(Figs 1, 2, 4A, B, D, E)

Diagnosis. Body size: 514-564 × 332-365. Body surface macrofoveolate and microgranulate. Lamellar cusp distally with strong triangular inner part and very small lateral (outer) tooth. Rostral, lamellar and interlamellar setae long, stiff, pointed apically, barbed. Bothridial seta very long, clavate, barbed. Notogastral setae stiff, pointed apically, barbed; posterior setae $p_{1}-p_{3}$ short, $c_{2}$ 
and $h_{1}$ slightly longer, other setae of medium length. Epimeral and anogenital setae short, slightly stiff, pointed apically, barbed. Leg trochanter IV with strong triangular process distodorsally.

Description of adult. Measurements. Body length: 514 (holotype: male), 514-564 (six paratypes: one male and five females); notogaster width: 332 (holotype), 332-365 (six paratypes).

Integument (Figs 4A, B, E). Body pale yellow. Surface foveolate (diameter of foveola up to 12) and densely microgranulate (diameter of granule less than 1), covered by thin layer of colorless, gel-like cerotegument.

Prodorsum (Figs 1A, C; 4A, D). Rostrum with rectangular ledge, two incisions and two lateral triangular teeth. Lamella (without cusp) as long as half of prodorsum. Lamellar cusp of medium size, distally with strong triangular inner part and very small lateral (outer) tooth. Lamellar cusps parallel, slightly divergent apically, connected basally by one small, triangular interlamellar tubercle. Rostral (49-53), lamellar (57-65) and interlamellar (53-65) setae stiff, pointed apically, barbed; ro thinner than others, le inserted on dorsal side of lamellar cusp. Bothridial seta (98-106) clavate, barbed, with long stalk and short, rounded distally head. Exobothridial seta not observed. Tutorium long, ridge-like.

Notogaster (Figs 1A, C; 2A, D, E). Anterior notogastral margin straight. Eleven pairs of notogastral setae $\left(c_{2}, h_{1}: 20-28 ; p_{1}-p_{3}: 12-16\right.$; others: $\left.36-45\right)$ stiff, pointed apically, barbed. Opisthonotal gland opening and all lyrifissures well visible.

Gnathosoma (Figs 2A-C; 4B). Subcapitulum longer than wide (147-151 × 106-110). All subcapitular $(a, h: 24-26 ; m: 32)$ and adoral (18-20) setae setiform, barbed. Palp (82-86) with setation: $0-2-1-3-9(+\omega)$. Postpalpal seta (6) spiniform, smooth. Chelicera (147-155) with two setiform, barbed setae (cha: 49-53; chb: 32-36).

Epimeral and lateral podosomal regions (Figs 1B, C). Epimeral setal formula: 3-1-3-3. All epimeral setae (1b:24,1c: 12; others: 20$)$ slightly stiff, pointed apically, barbed. Circumpedal carina present, thin.

Anogenital region (Figs 1B, C; 4B). Five pairs of genital (12-16), one pair of aggenital (16-20), two pairs of anal (16-20), and three pairs of adanal (16-20) setae slightly stiff, pointed apically, barbed.

Legs (Figs 2D-G; 4A, B). Median claw thicker than lateral claws, all slightly barbed on dorsal side. Femur I with small tubercle distoventrally, femur II with narrowly triangular process distoventrally, femora III and IV broadly triangular ventrodistally. Trochanter IV with strong triangular process distodorsally. Dorsoparaxial porose area on all femora and on trochanters III, IV distinct. Formulas of leg setation and solenidia: I (1-5-3-4-20) [1-2-2], II (1-4-2-4-16) [1-1-2], III (2-3-1-3-15) [1-1-0], IV (1-2-2-3-12) [0-1-0]; homology of setae and solenidia indicated in Table 1.

Material examined. Holotype (female) and six paratypes (one male and five females):

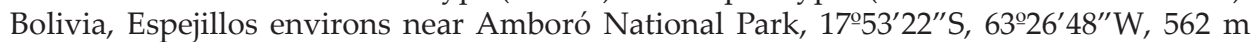
a.s.l., sifting leaf litter in rain forest, 29.XI.2009 (collected by B. GREENWAY).

Type deposition. The holotype is deposited in the collection of the SMNH; five paratypes are deposited in the collection of the TSUMZ. All specimens are preserved in $70 \%$ solution of ethanol with a drop of glycerol.

Etymology. The specific name pseudobolivianus refers to the similarity between the new species and X. bolivianus J. Balogh \& P. Balogh, 1985. 


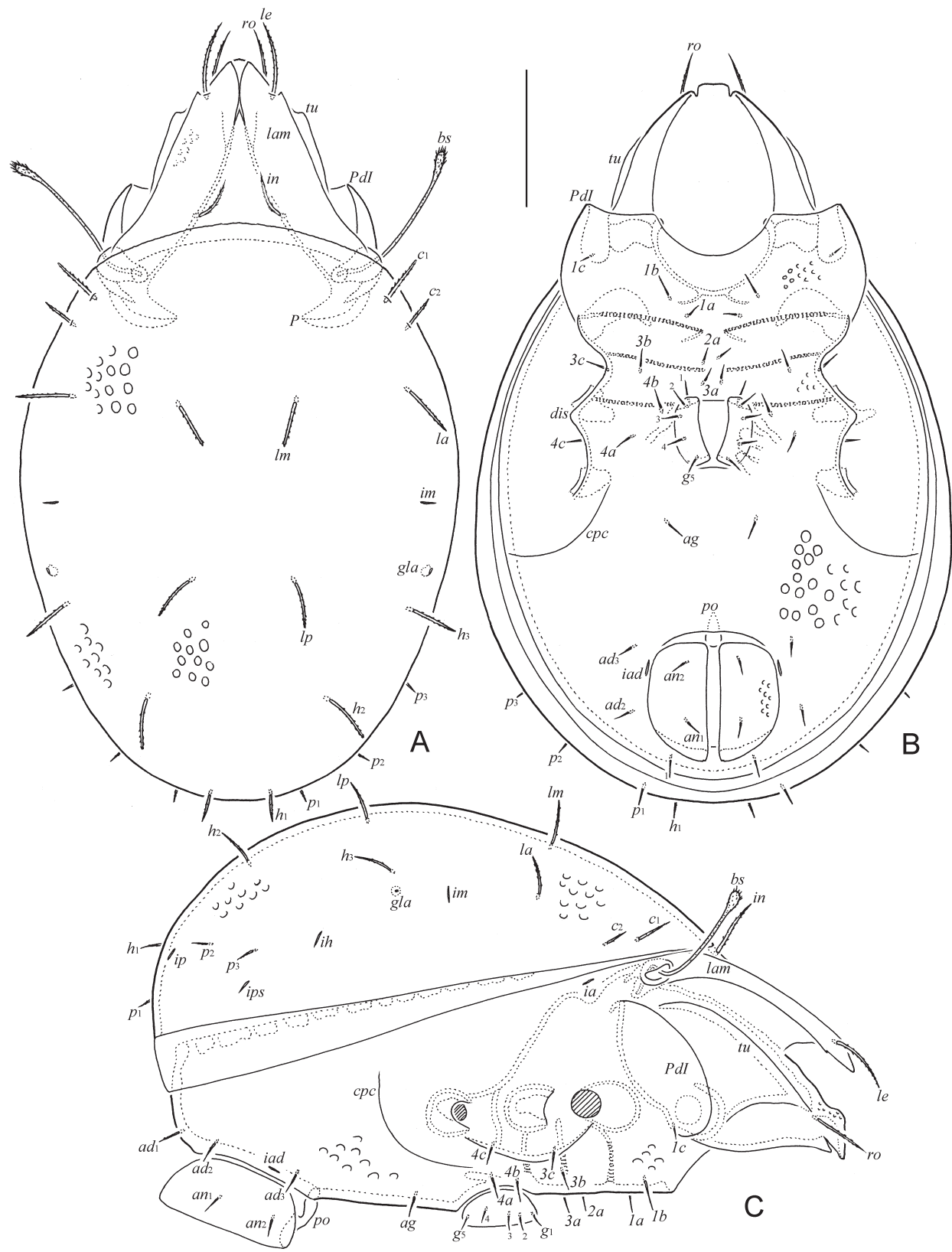

Fig. 1. Xenillus pseudobolivianus sp. $\mathbf{n}$., adult: $A=$ dorsal view; $B=$ ventral view (gnathosoma and legs not shown); $C=$ lateral view (gnathosoma and legs not shown). Scale bar: $100 \mu \mathrm{m}$ 


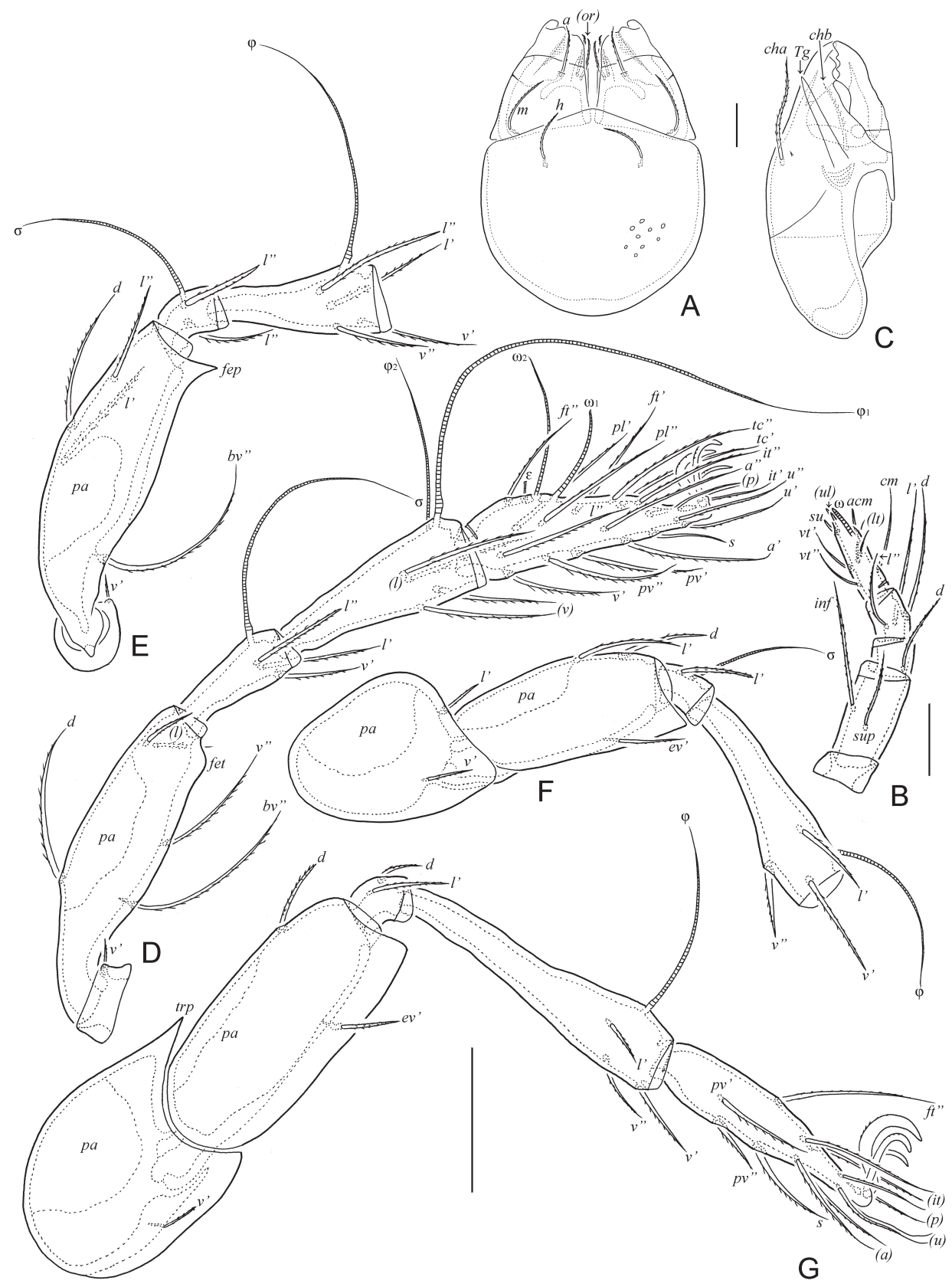

Fig. 2. Xenillus pseudobolivianus sp. n., adult: $\mathrm{A}=$ subcapitulum, ventral view; $\mathrm{B}=$ palp, left, antiaxial view; C = chelicera, left, paraxial view; D = leg I, right, antiaxial view; E = leg II, without tarsus, right, antiaxial view; F = leg III, without tarsus, left, antiaxial view; $\mathrm{G}=$ leg $\mathrm{IV}$, left, antiaxial view. Scale bars: $20 \mu \mathrm{m}(\mathrm{A}-\mathrm{C}), 50 \mu \mathrm{m}(\mathrm{D}-\mathrm{G})$ 
Table 1. Leg setation and solenidia of adult Xenillus pseudobolivianus sp. $\mathbf{n}$. and X. amboroensis sp. $\mathbf{n}$.

\begin{tabular}{lccccc}
\hline Leg & Tr & $F e$ & $G e$ & $T i$ & $T a$ \\
\hline I & $v^{\prime}$ & $d,(l), b v^{\prime \prime}, v^{\prime \prime}$ & $(l), v^{\prime}, \sigma$ & $(l),(v), \phi_{1^{\prime}} \phi_{2}$ & $\begin{array}{c}(f t),(t c),(i t),(p),(u),(a), s,(p v), v^{\prime}, \\
(p l), l^{\prime \prime}, \varepsilon, \omega_{1}, \omega_{2}\end{array}$ \\
II & $v^{\prime}$ & $d,(l), b v^{\prime \prime}$ & $(l), v^{\prime *}, \sigma$ & $(l),(v), \phi$ & $(f t),(t c),(i t),(p),(u),(a), s,(p v), l^{\prime \prime}$, \\
III & $l^{\prime}, v^{\prime}$ & $d, l^{\prime}, e v^{\prime}$ & $l^{\prime}, \sigma$ & $l^{\prime},(v), \phi$ & $(f t),(t c),(i t),(p),(u),(a), s,(p v)$ \\
IV & $v^{\prime}$ & $d, e v^{\prime}$ & $d, l^{\prime}$ & $l^{\prime},(v), \phi$ & $f t^{\prime \prime},(t c),(p),(u),(a), s,(p v)$ \\
\hline
\end{tabular}

Note: Roman letters refer to normal setae, Greek letters to solenidia (except $\varepsilon=$ famulus), single quotation mark (') designates setae on the anterior and double quotation mark (") setae on the posterior side of a given leg segment. Parentheses refer to a pair of setae. $v^{\prime *}$ - this seta present in X. amboroensis (versus absent in X. pseudobolivianus)

Remarks. In general morphological traits (lamellar cusp with strong triangular inner part; bothridial seta very long, clavate; interlamellar seta long; dorsal notogastral setae of medium length, stiff), Xenillus pseudobolivianus sp. $\mathbf{n}$. is most similar to two Bolivian species, X. bolivianus J. Balogh et P. Balogh, 1985 and X. neonominatus Subías, 2004 (= X. punctulatus J. Balogh et P. Balogh, 1985) (see J. BALOGH \& P. BALOGH 1985). However, the new species differs from the former by the presence of small, barbed bothridial head (versus bothridial head elongate, smooth), barbed interlamellar seta (versus interlamellar seta smooth), foveolate notogaster (versus notogaster not foveolate), and different length of some notogastral setae, e.g. $c_{1}$ longer than $c_{2}$ (versus $c_{1}$ and $c_{2}$ similar in length), $h_{1}$ shorter than dorsal notogastral setae (versus $h_{1}$ similar to dorsal notogastral setae in length); from the latter by the smaller body size (514-564 $\times$ 332-365 versus $750 \times 492$ ), clavate bothridial head (versus bothridial head lanceolate), barbed interlamellar and notogastral setae (versus interlamellar and notogastral setae smooth), foveolate notogaster (versus notogaster not foveolate), and different length of some notogastral setae, e.g. posterior notogastral setae $h_{1}$ and $p_{1}-p_{3}$ distinctly shorter than other dorsal notogastral setae (versus $h_{1}, p_{1}-p_{3}$ and dorsal notogastral setae similar in length).

Xenillus amboroensis Ermilov et Starý sp. n.

$$
\text { (Figs 3, 4C, F, G) }
$$

Diagnosis. Body size: 630-747 × 415-514. Body surface macrofoveolate and microgranulate. Lamellar cusp distally with small inner and outer processes (teeth) and indistinct concavity between them. Rostral, lamellar and interlamellar setae long, stiff, ro pointed apically, barbed, le and in blunted apically, heavily barbed; ro thinner than others, le bent medially, inserted 


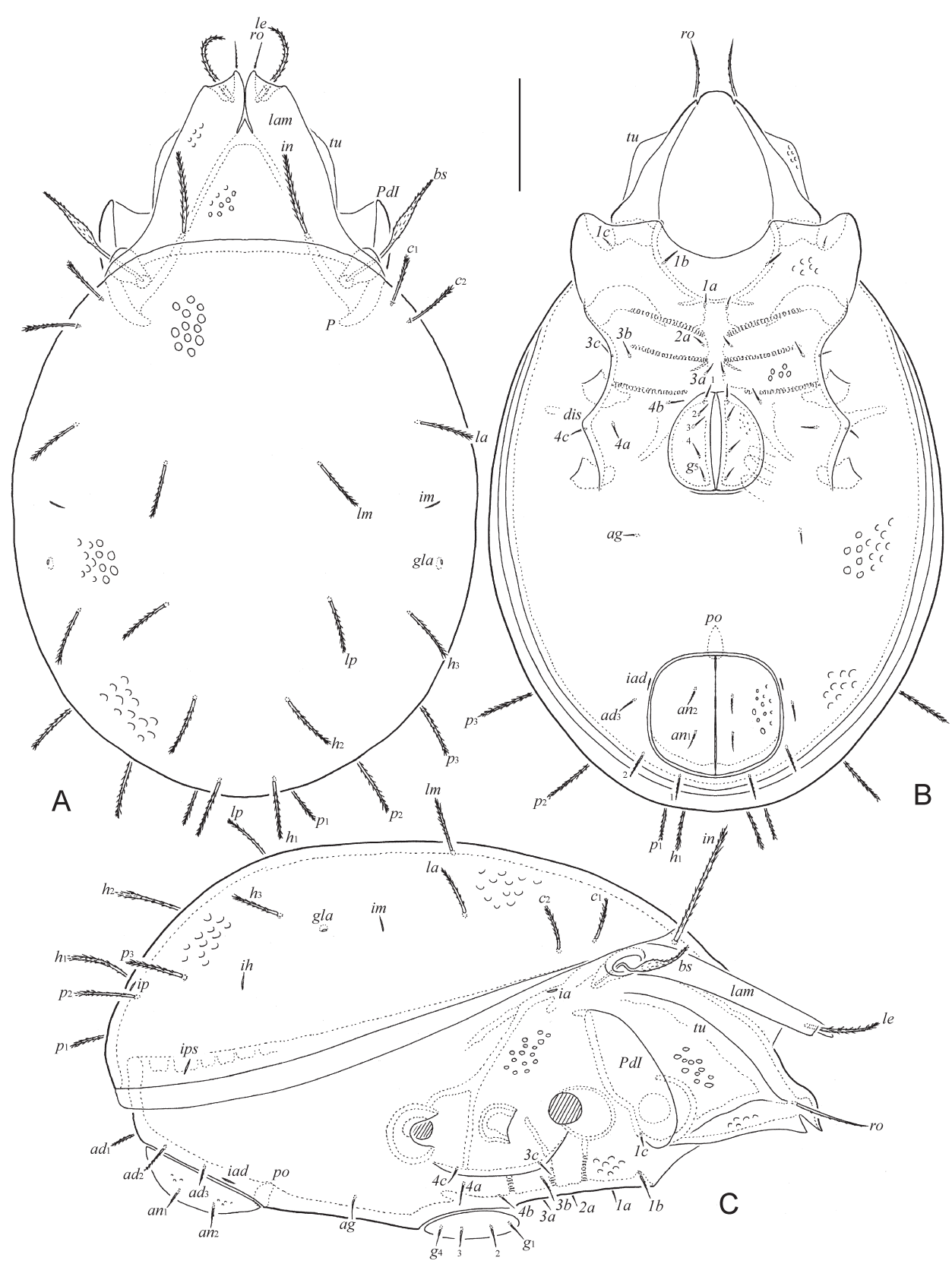

Fig. 3. Xenillus amboroensis sp. n., adult: $\mathrm{A}=$ dorsal view; $\mathrm{B}=$ ventral view (gnathosoma and legs not shown); C = lateral view (gnathosoma and legs not shown). Scale bar: $100 \mu \mathrm{m}$ 
on ventral side of lamellar cusp. Bothridial seta of medium length, fusiform, heavily barbed, with well-developed stalk, fusiform head and stiff apex. Notogastral setae of medium length ( $p_{1}$ shorter than others), stiff, blunted or indistinctly dilated apically, heavily barbed. Epimeral and anogenital setae short, slightly stiff, pointed apically, barbed; $a d_{1}$ and $a d_{2}$ longer than others.

Description of adult. Measurements. Body length: 664 (holotype: female), 630-747 (three paratypes: three females); notogaster width: 431 (holotype), 415-514 (three paratypes).

Integument (Figs 4S, F, G). Body brown. Surface foveolate (diameter of foveola up to 12) and densely microgranulate (diameter of granule less than 1), covered by a thin layer of colorless, gel-like cerotegument.

Prodorsum (Figs 3A, C; 4C, F). Rostrum with rectangular ledge, two incisions and two lateral triangular teeth. Lamella (without cusp) as long as half of prodorsum. Lamellar cusp of medium size, distally with small inner and outer processes (teeth) and indistinct concavity between them. Lamellar cusps parallel, slightly divergent apically, connected basally by one small, triangular interlamellar tubercle. Rostral seta (65-73) stiff, pointed apically, barbed; lamellar (82-94) and interlamellar (102-110) setae stiff, blunted apically, heavily barbed; ro thinner than others, le bent medially, inserted on ventral side of lamellar cusp. Bothridial seta (90-102) fusiform, heavily barbed, with well-developed stalk, fusiform head and stiff, blunted apically apex. Exobothridial seta not observed. Tutorium long, ridge-like.

Notogaster (Figs 3A, C; 4C, F, G). Anterior notogastral margin straight. Eleven pairs of notogastral setae $\left(p_{1}\right.$ : 36-45; others: 53-65) stiff, blunted or indistinctly dilated apically, heavily barbed. Opisthonotal gland opening and all lyrifissures well visible.

Gnathosoma. Generally, similar to Xenillus pseudobolivianus sp. n. Subcapitulum longer than wide (151-155 × 110-114). All subcapitular ( $a$ : 20; $m: 36 ; h$ : 16-20) and adoral (16-18) setae setiform, barbed. Palp (102-106) with setation: 0-2-1-3-9(+⿳). Postpalpal seta (6) spiniform, smooth. Chelicera (164-168) with two setiform, barbed setae (cha: 49-53; chb: 32-36).

Epimeral and lateral podosomal regions (Figs 3B, C). Epimeral setal formula: 3-1-3-3. All epimeral setae $(1 b, 3 b$ : 20-24, 1c: 10-12; 4a, 4b: 16-20; others: 12-16) slightly stiff, pointed apically, barbed. Circumpedal carina not observed.

Anogenital region (Figs 3B, C). Four pairs (two specimens with four seta on one plate and five setae on other plate) of genital (16-20), one pair of aggenital (16-20), two pairs of anal (16-20), and three pairs of adanal $\left(a d_{1}, a d_{2}: 28-36 ; a d_{3}: 16-20\right)$ setae slightly stiff, pointed apically, barbed.

Legs (Fig. 4C). Generally, similar to Xenillus pseudobolivianus sp. n. Median claw thicker than lateral claws, all slightly barbed on dorsal side. Femur I with small tubercle distoventrally, femur II with narrowly triangular process distoventrally, femora III and IV broadly triangular ventrodistally. Dorsoparaxial porose area on all femora and on trochanters III, IV distinct. Formulas of leg setation and solenidia: I (1-5-3-4-20) [1-2-2], II (1-4-3-4-16) [1-1-2], III (2-3-1-3-15) [1-1-0], IV (1-2-2-3-12) [0-1-0]; homology of setae and solenidia indicated in Table 1.

Material examined. Holotype (female) and three paratypes (three females): Bolivia,

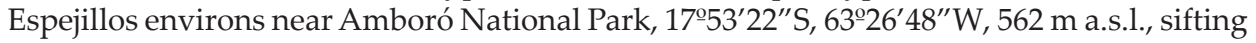
leaf litter in rain forest, 29.XI.2009 (collected by B. GreEnwAy).

Type deposition. The holotype is deposited in the collection of the SMNH; three paratypes are deposited in the collection of the TSUMZ. All specimens are preserved in $70 \%$ solution of ethanol with a drop of glycerol. 


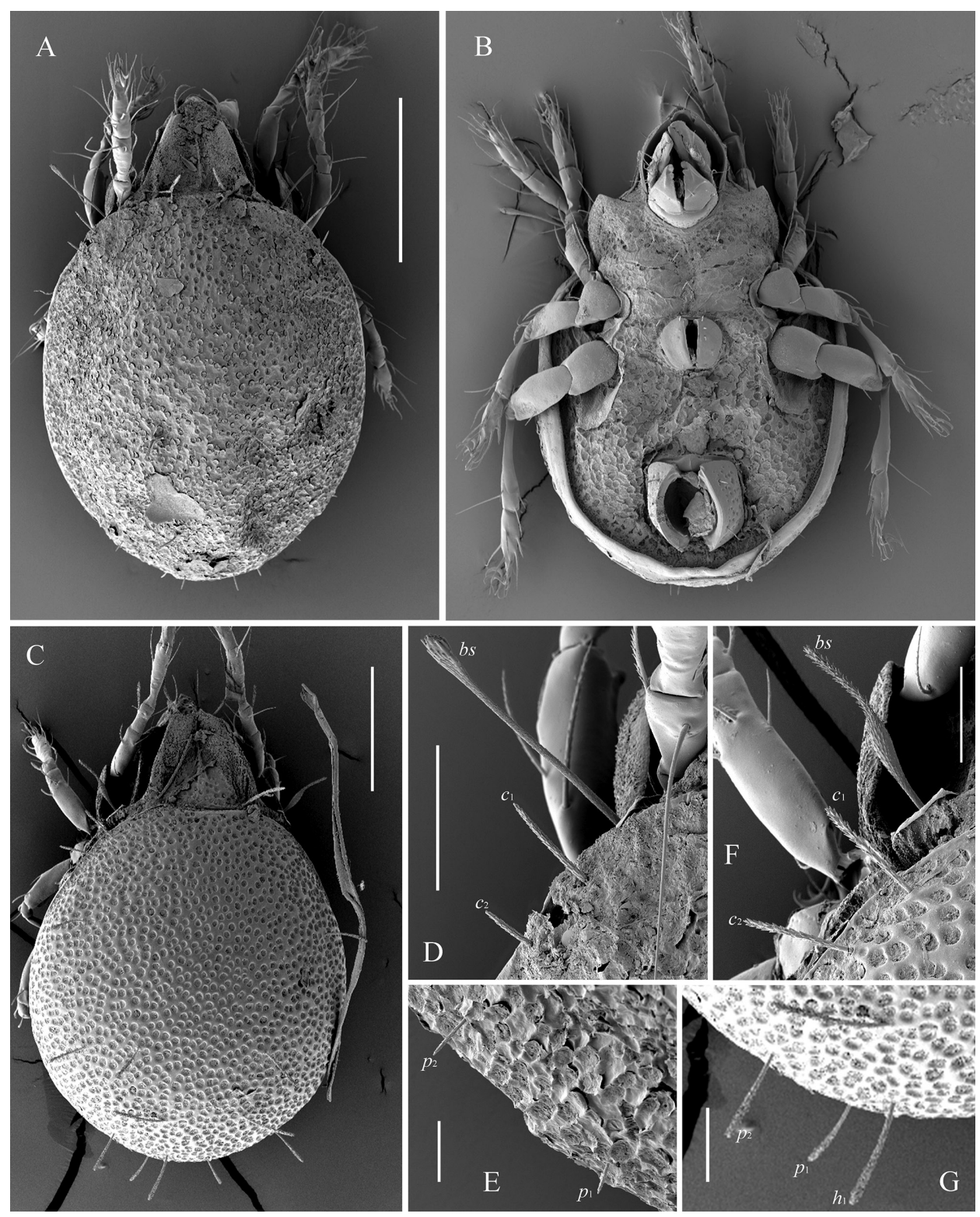

Fig. 4. Xenillus pseudobolivianus sp. n. (A, B, D, E) and X. amboroensis sp. n. (C, F, G), adults, SEM micrographs (SEM HV: 5kV): A (view field: $816 \mu \mathrm{m}$; WD: $14.30 \mathrm{~mm}$ ), B (view field: $689 \mu \mathrm{m}$; WD: $14.47 \mathrm{~mm}$ ) = ventral view; $C$ (view field: $1.09 \mathrm{~mm}$; WD: $14.21 \mathrm{~mm}$ ) = dorsal view; D (view field: $174 \mu \mathrm{m}$; WD: $14.30 \mathrm{~mm}$ ), E (view field: $159 \mu \mathrm{m}$; WD: $14.43 \mathrm{~mm}$ ); F (view field: $239 \mu \mathrm{m}$; WD: $14.18 \mathrm{~mm}$ ) = bothridial seta and humeral notogastral setae; $\mathrm{G}$ (view field: $1.09 \mathrm{~mm}$; WD: $14.21 \mathrm{~mm}$ ) = some posterior notogastral setae. Scale bars: $200 \mu \mathrm{m}$ $(\mathrm{A}-\mathrm{C}), 50 \mu \mathrm{m}(\mathrm{D}, \mathrm{F}), 20 \mu \mathrm{m}(\mathrm{E}, \mathrm{G})$ 
Etymology. The specific name amboroensis refers to the Amboró National Park, near which the type material was collected.

Remarks. In having fusiform bothridial seta with long, stiff apex, Xenillus amboroensis sp. $\mathrm{n}$. is similar to Xenillus amazonensis Pérez-Iñigo et Baggio, 1997 from Brazil (see Pérez-Í̃̃ IGo \& BAGgio 1997), X. disjunctus Balogh et Mahunka, 1977 from Chile (see Balogh \& Mahunka 1977), X. diversisetosus P. Balogh, 1986, X. fecundus P. Balogh, 1986 and X. longipes Mahunka, 1984 from the Neotropical region (see P. BAlogh 1986, MAhunKa 1984), and X. ornatus (Covarrubias, 1967) from Chile (Covarrubias 1967). However, the new species differs from the species listed above by the following characters: lamellar cusp distally with small inner and outer teeth and indistinct concavity between them (versus cusp with large inner and outer teeth and deep indentation between them in $X$. amazonensis, $X$. diversisetosus, $X$. fecundus, and X. longipes; cusp triangular in $X$. disjunctus and $X$. ornatus); lamellar seta located on ventral side of lamellar cusp (versus lamellar seta located distally on lamellar cusp in X. amazonensis, $X$. longipes and X. ornatus; lamellar seta located on dorsal side of lamellar cusp in X. disjunctus, X. diversisetosus and X. fecundus); and all notogastral setae of medium length, stiff, heavily barbed (versus notogastral setae $h_{1}$ and $p_{1}-p_{3}$ short, simple in $X$. amazonensis; some notogastral setae long in $X$. disjunctus, $X$. diversisetosus, $X$. longipes, and $X$. ornatus; setae $c_{1}$ and $c_{2}$ shorter than others in $X$. fecundus).

Acknowledgements - The authors would like to thank Dr. B. Greenway (London, UK), a coleopterologist, for collecting soil samples in Bolivia; and two anonymous reviewers for their valuable comments. This research was supported by the cooperative agreement No. FEWZ-2021-0004 from the Russian Ministry of Science and Higher Education.

\section{REFERENCES}

Balogh, J. \& BAlogh, P. (1985): Fifteen new species of the genus Xenillus Robineau-Desvoidy, 1839 (Acari: Oribatei) from South America. - Acta Zoologica Hungarica 31(1-3): 53-79.

Balogh, J. \& Balogh, P. (1988): Oribatid mites of the Neotropical region. I. - Elsevier Science Publishers, Amsterdam and Akadémiai Kiadó, Budapest, 335 pp.

Balogh, J. \& Balogh, P. (2002): Identification keys to the oribatid mites of the Extra-Holarctic regions. Vol. 1. - Well-Press Publishing Limited, Miskolc, 453 pp.

Balogh, J. \& Mahunka, S. (1969): The scientific results of the Hungarian soil zoological expeditions to South America. 12. Acari: Oribatids from the materials of the second expedition. III. - Acta Zoologica Academiae Scientiarum Hungaricae 15(3-4): 255-275.

Balogh, J. \& MahunKa, S. (1977): New data to the knowledge of the oribatid fauna of Neogea (Acari). II. - Acta Zoologica Academiae Scientiarum Hungaricae 23(3-4): 247-265. 
Balogh, P. (1985): The species of the genus Xenillus Robineau-Desvoidy, 1839 in the Neogea (Acari: Oribatei). - Opuscula Zoologica, Budapest 21: 41-62.

Balogh, P. (1986): Four new Xenillus species from the Neotropical region (Acari: Oribatei). - Opuscula Zoologica, Budapest 22: 43-50.

Covarrubias, R. (1967): New oribatids (Acarina) from Chile. - Opuscula Zoologica, Budapest 7(2): 89-116.

Grobler, L., Ozman, S. K. \& Cobanoglu, S. (2003): The genera Liacarus, Stenoxenillus and Xenillus (Oribatida: Gustavioidea) from Turkey. - Acarologia 43(1): 133-149.

MahunKa, S. (1984): Neue und interessante Milben aus dem Genfer Museum XLVIII. Oribatida Americana 8: Paraguay I (Acari). - Revue Suisse de Zoologie 91(1): 109-147. https://doi.org/10.5962/bhl.part.81870

MAhunKa, S. \& Zombori, L. (1985): The variability of some morphological features in oribatid mites. - Folia Entomologica Hungarica 46(1): 115-128.

Norton, R. A. (1977): A review of F. Grandjean's system of leg chaetotaxy in the Oribatei (Acari) and its application to the family Damaeidae. Pp. 33-61. In: Dindal, D. L. (ed.): Biology of oribatid mites. - SUNY College of Environmental Science and Forestry, Syracuse.

Norton, R. A. \& Behan-Pelletier, V. M. (2009): Suborder Oribatida. Chapter 15. Pp. 430564. In: Krantz, G. W. \& Walter, D. E. (eds): A manual of acarology. - Texas Tech University Press, Lubbock.

Pérez-ÍñIgo, C. \& BAggio, D. (1997): Oribates édaphiques du Brésil (X). Quelques Oribates de l'État de Para. - Acarologia 38(4): 403-413.

Robineau-Desvoidy, D. M. (1839): Mémoire sur le Xenillus clypeator (Coléoptère nouveau). - Annales de la Société Entomologique de France 8: 455-462.

Subías, L. S. (2004): Listado sistemático, sinonímico y biogeográfico de los ácaros oribátidos (Acariformes, Oribatida) del mundo (1758-2002). - Graellsia 60(número extraordinario): 3-305. https://doi.org/10.3989/graellsia.2004.v60.iExtra.218

Subías, L. S. (2021): Listado sistemático, sinonímico y biogeográfico de los Ácaros Oribátidos (Acariformes: Oribatida) del mundo (excepto fósiles), 16 actualización. 532 pp. Available from: bba.bioucm.es/cont/docs/RO_1.pdf

Travé, J. \& Vachon, M. (1975): François Grandjean. 1882-1975 (Notice biographique et bibliographique). - Acarologia 17(1): 1-19.

Weigmann, G. (2006): Hornmilben (Oribatida). Die Tierwelt Deutschlands. Teil 76. - Goecke and Evers, Keltern, 520 pp.

Received April 9, 2021, accepted July 12, 2021, published November 19, 2021 
